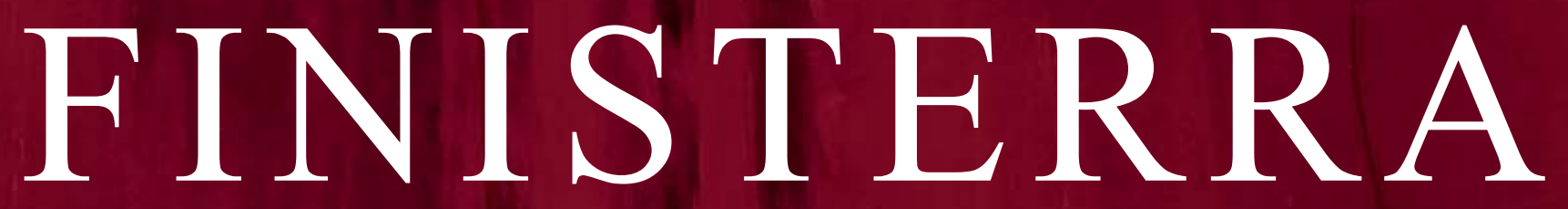

Revista Portuguesa de Geografia

Centro

de Estudos

Geográficos

Volume LII

Número 106

Dezembro 2017 


\title{
O HOTEL SANTIAGO DE ALFAMA COMO ALEGORIA DA POLÍTICA RECENTE DE REGENERAÇÃO URBANA
}

JoÃO SAFARA ${ }^{1}$

EDUARDO BRITO-HENRIQUES ${ }^{2}$

\begin{abstract}
RESUMO - Este artigo tem por objetivo discutir a turistificação urbana, nas suas relações com o urbanismo neoliberal e a reestruturação urbana no capitalismo globalizado, procurando mais particularmente averiguar o papel que a iniciativa JESSICA, enquanto instrumento de política neoliberal para a regeneração urbana, teve na turistificação da cidade de Lisboa. O artigo baseia-se numa metodologia de investigação micro-geográfica, procedendo a um estudo de caso detalhado, com a reconstituição da biografia de um edifício que foi recentemente convertido para hotel de luxo com financiamento JESSICA. O estudo mostra que, nessa mudança funcional, ocorreu uma elitização do local, e que a turistificação veio ocupar o vazio deixado após um longo período de desinvestimento e abandono gradual do edifício. O estudo conclui ainda que a turistificação deve ser vista como uma consequência e um reflexo da globalização na transformação da cidade, e que o fundo JESSICA não encaminhou mas antes se limitou a coadjuvar uma intenção de investimento que já estava latente.

Palavras-chave: turistificação; regeneração urbana; iniciativa JESSICA; biografia de edifícios.
\end{abstract}

ABSTRACT - THE SANTIAGO DE ALFAMA HOTEL AS AN ALLEGORY OF THE RECENT URBAN REGENERATION POLICY. This paper aims to discuss the process of urban touristification, and its relationship with neoliberal urbanism and urban restructuring in the era of global capitalism. In particular, the paper examines the role played by the Jessica initiative, as an instrument of neoliberal policy for the urban regeneration, in the touristification of the Lisbon city. This paper is based on a micro-geographical investigation, in which a detailed case study was conducted to reconstitute the biography of a building that has recently been converted into a luxury hotel using Jessica financing. The study shows that

Recebido: maio 2017. Aceite: agosto 2017.

1 Doutorando em Turismo no Instituto de Geografia e Ordenamento do Território da Universidade de Lisboa, R. Branca Edmée Marques, 1600-276, Lisboa, Portugal. E-mail: joao.safara@campus.ul.pt

2 Professor Associado e Investigador Efetivo do Centro de Estudos Geográficos do Instituto de Geografia e Ordenamento do Território da Universidade de Lisboa, R. Branca Edmée Marques, 1600-276, Lisboa, Portugal. E-mail: eduardo@igot.ulisboa.pt 
under this functional change there was an elitization of the locale and that touristification filled the void left after a long period of disinvestment and a gradual abandonment of the building. The study concludes that touristification should be seen as a consequence and a reflection of globalizing processes underlying the transformation of the city. The Jessica Fund did not guide but merely assist the investment intention that was already latent.

Keywords: Touristification; urban regeneration; JESSICA initiative; house biographies.

RESUMÉ - L'HÔTEL SANTIAGO DE ALFAMA, EN TANT QUE SYMBOLE DE LA POLITIQUE RÉCENTE DE RÉGÉNÉRATION URBAINE. On a cherché ici à comprendre le phénomène de «touristification» urbaine, dans le cadre de l'urbanisation néolibérale et de la restructuration urbaine liée au capitalisme mondialisé. On a cherché en particulier quel fut le rôle de l'initiative JESSICA, cet instrument de la politique néolibérale pour la rénovation urbaine, dans la «touristification» de la ville de Lisbonne. La méthode de recherche a été micro-géographique, par la réalisation d'une étude de cas détaillée, la reconstitution «biographique» d'un immeuble récemment converti en hôtel de luxe grâce au financement JESSICA. Ce changement fonctionnel a provoqué l' «élitisation» d'un lieu qui était demeuré vide après une longue période de désinvestissement et d'abandon progressif de lédifice. On montre aussi que la «touristification» est une conséquence directe de la mondialisation sur la transformation de la ville, le fonds JESSICA ayant seulement appuyé une intention d'investissement qui était déjà latente.

Mots clés: «Touristification»; régénération urbaine; initiative JESSICA; biographie d'immeuble.

\section{INTRODUÇÃO}

\section{Objetivos do estudo}

Este artigo é sobre a articulação entre políticas públicas, turismo e reestruturação urbana no capitalismo globalizado. Um tema sobre o qual se produziu vasta bibliografia nas últimas décadas, mas que está longe de se encontrar esgotado.

Neste artigo, propomo-nos examinar esse nexo a partir de um instrumento de política em particular: o fundo JESSICA e a sua aplicação em Portugal. A iniciativa JESSICA representou a última geração de instrumentos de política de regeneração urbana da União Europeia (UE). Foi uma experiência inovadora de engenharia financeira aplicada à política de cidades e, nessa qualidade, corresponde a uma solução que encaixa no que, não sem crítica, tem sido designado de "urbanismo neoliberal" (Peck, Theodor, Brenner, 2009). Apesar de ter sido concebida como um instrumento de política para o desenvolvimento urbano sustentável, com ações elegíveis que recobrem um vasto espectro de domínios desde as mobilidades suaves à eficiência energética ou às TIC, em Portugal a iniciativa JESSICA foi canalizada maioritariamente para o turismo. Nas cidades de Lisboa e do Porto, mais de $62 \%$ dos fundos JESSICA foram aplicados em investimentos turísticos, designadamente alojamento (dados reportados no fim de 2015 pelo Jessica Holding 
Fund, quando praticamente todo o montante estava utilizado). Embora se encontrem referências à iniciativa JESSICA em estudos recentes sobre a política de cidades (Barata Salgueiro, André \& Brito-Henriques, 2015), está por fazer uma análise consistente do uso deste instrumento de política e dos seus efeitos e ainda não houve uma reflexão suficientemente profunda sobre a sua relação com o turismo, lacuna que o estudo que aqui se apresenta procura suprir.

Sinteticamente, podemos dizer que este artigo tem em vista dois objetivos: i) primeiro - e em termos mais gerais -, discutir a turistificação na sua relação com a transformação das cidades no capitalismo globalizado, entendendo por "turistificação" o processo de transmutação urbana em que novas infraestruturas, atividades e ambiências criadas pelo e para o turismo tomam o lugar das funções tradicionais urbanas (Jansen-Verbeke \& Lievois, 1999); ii) e em segundo lugar, analisar a iniciativa JESSICA enquanto instrumento de regeneração urbana e o seu contributo para a turistificação da cidade.

\section{Metodologia e organização do artigo}

O estudo de caso é uma estratégia de investigação que procura compreender um dado fenómeno social através da examinação detalhada de um caso ou de um número reduzido de casos que são expressões desse fenómeno (Stake, 1995). Subjacente está a ideia de que, através de uma descrição atentiva do caso selecionado, é possível identificar e expor as causas e os mecanismos que produzem o fenómeno assim como os agentes envolvidos.

Nesta pesquisa usa-se um tipo particular de estudo de caso inspirado nas biografias de casas (house biographies). Este termo descreve um género de estudos micro-geográficos que procura "iluminar a história de uma casa particular através das vidas dos seus vários residentes” (Blunt \& Dowling, 2006, p. 39). As biografias de casas diferem das clássicas monografias de edifícios desenvolvidas na arquitetura e na história da arte na medida em que não se centram na crítica da materialidade do edificado. Versam uma abordagem mais holística que inclui a dimensão da cultura material, mas que se estende também à política e à sociologia ao colocarem o foco na relação do imóvel com os seus habitantes e proprietários (Blunt, 2008). Para Althaus e Glaser (2015), a biografia de casa pode ser descrita como uma narrativa das mudanças que um imóvel teve ao longo da sua vida, não só em termos das condições físicas ou estruturais, mas também de usos e apropriações, de experiências e de discursos. O propósito último é apreender as mudanças na cidade usando um prisma de microescala urbana, i.e. através de histórias particulares e da relação das pessoas com imóveis em concreto (Jacobs, Cairns, Strebel, 2012; Althaus \& Glaser, 2015).

Embora ainda raros, começam a surgir estudos deste tipo sobre edifícios de hotéis (v. Goh, 2010). Neste artigo, é uma abordagem desse género que fazemos aplicada a um hotel de luxo situado no centro histórico de Lisboa - o Hotel Santiago de Alfama. Trata-se de um pequeno estabelecimento hoteleiro com menos de vinte quartos, instalado num edifício histórico e pertencente a uma nova geração de hotéis surgidos em Lisboa nos últimos anos que beneficiaram do fundo JESSICA. 
No processo de recolha de dados para o desenvolvimento deste estudo de caso usámos uma abordagem multimétodo. Esta incluiu análise nos arquivos e registos históricos do imóvel junto da Câmara Municipal de Lisboa (CML) e na Conservatória Predial, mas também recolha direta de informação in situ e a partir de fontes primárias. Realizaram-se visitas ao imóvel para observação direta, assim como entrevistas semiestruturadas com o (i) atual proprietário do imóvel, (ii) o arquiteto responsável pelo projeto de reabilitação e pela condução das obras de adaptação do edifício, (iii) e funcionários do Turismo de Portugal, I.P. (TdP), entidade à qual coube a gestão do fundo JESSICA na região de Lisboa.

O corpo do artigo está organizado em quatro partes. Começamos com uma breve revisão da literatura para enquadrar teoricamente o problema em debate. Segue-se uma secção em que se apresenta e explica o funcionamento da iniciativa JESSICA, situando-a no contexto das políticas de regeneração urbana da União Europeia. A parte seguinte corresponde ao estudo do caso propriamente dito - a biografia do edifício do Hotel Santiago de Alfama - e a última parte do artigo é destinada à discussão final dos resultados e à conclusão.

\section{ENQUADRAMENTO TEÓRICO: JUNTANDO AS PEÇAS DO DEBATE}

\section{Reeestruturação urbana, globalização neoliberal e políticas regenerativas das cidades}

O termo reestruturação urbana começou a ser usado nos anos 80 para designar as metamorfoses produzidas nas cidades e metrópoles capitalistas pela crise do modelo económico industrial-fordista (Soja, Morales, \& Wolff, 1983). Através da lente deste conceito, tendências díspares e até contraditórias de desinvestimento e reinvestimento em diferentes setores da economia das cidades e em diferentes partes do tecido urbano puderam ser entendidas de forma concatenada, como expressões de uma desestruturação/reestruturação da configuração espacial da acumulação capitalista, ou, nos termos de Harvey (1982), de um "ajuste espacial" (spatial fix). Embora a teoria marxista e a teoria neoclássica divirjam quanto às causas da crise que espoletou este ajuste, está formado um amplo consenso na literatura quanto ao facto da desindustrialização, do abandono das áreas centrais das cidades e mesmo da contra-urbanização numa primeira fase, como depois dos movimentos contrários de reapropriação da centralidade pelos grupos mais afluentes da sociedade (gentrificação), de renovação e revitalização das frentes ribeirinhas, ou do aparecimento de novas centralidades terciárias associadas ao setor financeiro, ao consumo e à cultura, corresponderem a duas faces complementares dessa reestruturação urbana (Fainstein, 1990; Sassen, 2000; Zukin, 2010).

O nexo entre a reestruturação urbana e a globalização está consolidado na literatura. Tal como a reestruturação urbana, também a globalização é interpretada como um correlato da reestruturação pós-fordista e da correspetiva reorganização do capitalismo à 
escala mundial (Sassen, 2000). A globalização é ela própria vista como impulsora da reestruturação urbana. Essa presença da globalização na transformação das cidades é visível e tem sido assinalada no 'urbanismo de megaeventos' (Beriatos \& Gospodini, 2004; Broudehoux, 2007), no aumento de escala e financeirização do imobiliário e no investimento em projetos icónicos (Barata Salgueiro, 1994; Sklair, 2006; Fainstein, 2008), ou ainda na globalização da gentrificação (Smith, 2002; Rofe, 2003).

Está igualmente bem identificada e descrita na literatura a conexão entre globalização e neoliberalismo (Sager, 2011). O neoliberalismo formou o ambiente ideológico e o aparato de políticas necessário à globalização económica. Peck et al., (2009) assinalaram que esta conexão globalização-neoliberalismo é um fenómeno multiescalar que se exprime especialmente nas cidades. Dela resultou um novo paradigma de governo da cidade que se exprime em privatizações, parcerias público-privado, emulação de modelos empresariais na gestão urbana (o que inclui a descrença e abandono dos planos normativos de uso do solo e sua substituição por planeamento estratégico), assim como na priorização da competitividade e do crescimento sobre a equidade e a redistribuição (Hackworth, 2006; Peck et al., 2009).

A regeneração urbana, tornada a grande prioridade do planeamento urbano nos últimos trinta anos, é, para Hackworth (2006) entre outros, o instrumento político por excelência de efetivação da cidade neoliberal. Justifica-se discursivamente pela necessidade de superar o ciclo de declínio associado à desindustrialização, de promover a recuperação económica adaptando a cidade aos desafios da nova economia global e de reverter a regressão demográfica e o envelhecimento atraindo novos residentes, sobretudo da 'classe criativa'. A requalificação do edificado e do ambiente urbano ligadas à competitividade da cidade e ao marketing territorial são questões cruciais nas políticas regenerativas e nelas costumam estar igualmente presentes as novas soluções de planeamento e de governança associadas ao urbanismo neoliberal (Tallon, 2010; Guimarães, 2016).

\section{Regeneração urbana, turistificação e gentrificação}

A solução encontrada nas operações de regeneração urbana assenta normalmente num mix de cultura, consumo, entretenimento e capital imobiliário, combinado em doses variáveis (Hannigan, 1998; Fainstein \& Judd, 1999; Lloyd \& Clark, 2001). Os estudos desenvolvidos sobre os espaços e as formas construídas da regeneração urbana, sejam frentes ribeirinhas e docas renovadas (Goss, 1996; Edwards et al., 2008), centros das cidades revitalizados (Lloyd, 2002; Skoll \& Korstanje, 2014), locais de megaeventos (Beriatos \& Gospodini, 2004), ou projetos de 'redesenvolvimento' urbano em áreas abandonadas ou com usos obsoletos (Tallon, 2010), mostram um forte investimento nos aspetos da memória e do design, o que diz muito sobre o vínculo da regeneração urbana à "economia dos signos" (Lash \& Urry, 1994) e, por conseguinte, ao turismo.

Nos anos 90 percebeu-se que o turismo estava a emergir como alternativa ao desaparecimento da indústria nas cidades (Law, 1992). A transformação do espaço urbano pelo turismo tornou-se especialmente patente nessa nova categoria de espaços urbanos que 
Fainstein e Judd (1999) designaram "cidades convertidas", assim como na turistificação dos centros históricos (Jansen-Verbeke \& Lievois, 1999). Resultados positivos dessa ligação do turismo ao renascimento das cidades foram descritos em numerosos estudos (McCarthy \& Pollock, 1997; McCarthy, 1998; Orueta, 2007; Galdini, 2007; Foley \& McPherson, 2007; Ashworth \& Page, 2011).

Também em Portugal, e mais concretamente em Lisboa, há sinais dessa imbricação entre reconversão pós-industrial, políticas regenerativas, competitividade urbana e turismo desde os anos 90 (Brito Henriques, 1996). Datam dessa década os esforços para tornar Lisboa mais atrativa e competitiva, promovendo-a como um destino turístico urbano moderno. O Plano Estratégico de Lisboa de 1992 referia quatro objetivos estratégicos, sendo um precisamente tornar Lisboa competitiva no sistema das cidades europeias. A cidade iniciou então um programa ambicioso de valorização urbana e promoção da imagem externa, que envolveu a modernização de infraestruturas (rodovias e metropolitano), criação e renovação de equipamentos culturais, com intervenções arquitectónicas de grande escala e design sofisticado, e grandes operações de regeneração e 'redesenvolvimento' em áreas industriais obsoletas e na frente ribeirinha (Barata Salgueiro, 2001). A sediação da Presidência das Comunidades Europeias, em 1992, foi o pretexto para uma intervenção urbana de grande escala em Belém, com a construção do CCB. Entendia-se necessário projetar internacionalmente a imagem da cidade e, estrategicamente, os decisores públicos candidataram (com sucesso) Lisboa a Capital Europeia da Cultura (1994) e sede da Exposição Mundial de 1998, evento que foi motivo de uma transformação profunda na Lisboa Oriental, com a reconversão de antigas áreas industriais em espaços de recreio, de habitação de padrão elevado e de consumo.

Ao longo dos últimos anos, o turismo continuou a ser visto pelos decisores políticos (nacionais, regionais e locais) como uma alavanca para a regeneração urbana, designadamente em Lisboa. Essas relações entre turismo e regeneração urbana fortaleceram-se em especial e ganharam novas formas desde 2007, por um lado com o aparecimento de novos incentivos e instrumentos financeiros de promoção de turismo enquadrados pelas políticas regionais, por outro lado graças a um conjunto de alterações de flexibilização que se introduziram nos regimes jurídicos da reabilitação urbana, do arrendamento urbano, e do próprio alojamento turístico (Barata Salgueiro, Guimarães, \& Mendes, 2017).

O entusiasmo que as relações entre turismo e regeneração acima referidas descrevem tem sido no entanto matizado por posições que realçam a falta de autenticidade e o empobrecimento das relações sociais e da vida de rua devido à híper-securitização e estetização das áreas regeneradas pelo e para o turismo (Selby et al., 2008; Zukin, 2010). Outra crítica põe em destaque o facto dos bairros turistificados e precintos turísticos serem espaços segregados e potencialmente excludentes (Judd, 2003), o que nos últimos tempos evoluiu para uma crescente atenção às relações entre turismo e gentrificação.

O conceito de gentrificação turística, trabalhado inicialmente por Gotham (2005), aplica-se sobretudo a bairros residenciais históricos e coloca em destaque o efeito do turismo na transformação desses bairros, com a passagem de usos de habitação e comércio tradicional para usos turísticos e de entretenimento, que se repercutem no aumento 
do valor das propriedades imobiliárias. Tem-se referido que a expulsão dos residentes pode ocorrer de forma direta, indireta e induzida, através dos mecanismos contratuais e valor das rendas, mas também pelo sentimento de privação e exclusão no acesso a bens e a espaços de uso coletivo e pela perda do sentido de pertença ao lugar (Dirksmeier \& Helbrecht, 2015; Cócola Gant, 2015). Contudo, permanecem mal conhecidos os processos e mecanismos exatos da gentrificação e os atores nela envolvidos: Gotham (2005) considerou como atores chave as cadeias hoteleiras e de cafés e restaurantes, Gladstone e Préau (2008) puseram em destaque o papel dos trabalhadores jovens dos serviços turísticos e recreativos como gentrificadores, enquanto Füller e Michel (2014) colocam a tónica nos pequenos investidores que transferem casas do mercado residencial convencional para o arrendamento de curta duração. Além disso, não há consenso na literatura em relação ao balanço final dos efeitos do turismo na cidade e há razões para considerar que demonizar a gentrificação turística é uma forma simplista de encarar o problema (Skoll \& Korstanje, 2014). Embora boa parte da bibliografia recente coloque o foco nos conflitos gerados pela turistificação do espaço urbano, há estudos que sugerem que políticas restritivas do desenvolvimento do turismo e orientadas estritamente para as comunidades residentes são ineficazes e acabam por inibir a revitalização dos bairros históricos (Andrade \& Lamela, 2015).

\section{A INICIATIVA JESSICA NO QUADRO DOS INSTRUMENTOS DE POLÍTICA URBANA EUROPEUS}

Até aos anos 90 não havia no quadro europeu programas de políticas específicas para as cidades. As operações em áreas urbanas financiavam-se caso tivessem enquadramento nas prioridades das políticas regionais e apenas nesses casos. O primeiro instrumento de política de iniciativa comunitária pensado especificamente para as cidades - intitulado Projetos Pilotos Urbanos (PPU) - surgiu em 1990. Como a iniciativa URBAN, que representou uma evolução dos PPU, dirigia-se à revitalização económica e social de áreas urbanas em crise e assentava no apoio a projetos pontuais inovadores, o que dava às operações apoiadas um carácter de excecionalidade.

Foi já no presente século que a Comissão Europeia começou a conduzir uma política mais ativa em prol das cidades. Entre 2000 e 2006, a iniciativa URBAN II viu o seu envelope financeiro reforçado, passando a mobilizar conjugadamente FEDER e FSE. Com as assinaturas do Acordo de Bristol, em 2005, e da Carta de Leipzig, em 2007, a autonomia dos temas urbanos na agenda política europeia tornou-se mais evidente. $O$ lançamento do Programa Operacional URBACT em 2007 inscreveu-se nesse esforço. No entanto, foi através dos programas operacionais regionais que se continuou a fazer o essencial do financiamento do desenvolvimento urbano (Barata Salgueiro et al., 2015).

A iniciativa JESSICA - Joint European Support for Sustainable Investment in City Areas (Apoio Europeu Comum para o Investimento Sustentável em Zonas Urbanas) foi criada por uma decisão deliberativa da Comissão Europeia de 2006 (artigo $44^{\circ}$ ao $46^{\circ}$ do 
Regulamento n. ${ }^{\circ} 1083 / 2006$ e artigo $43^{\circ}$ ao $46^{\circ}$ do Regulamento $n^{\circ} 1828 / 2006$, ambos da Comissão Europeia). Contou com a colaboração do Banco Europeu de Investimento (BEI) e do Banco de Desenvolvimento do Conselho da Europa (BDCE) e o seu objetivo foi promover a regeneração e o desenvolvimento urbano sustentável apoiando financeiramente operações de empresas, parcerias público-privado e fundos de investimento.

A principal novidade da iniciativa JESSICA consistiu no modelo de funcionamento e gestão. A JESSICA assentou numa lógica de alavancagem de fundos públicos por capitais privados e de cooperação multinível entre instituições comunitárias e dos Estados-membros, tendo sido concebida para funcionar em moldes semelhantes aos fundos de capitais das sociedades financeiras, o que reflete uma tendência neoliberalizante da política urbana na UE. Para a operacionalização da JESSICA em Portugal, foi constituído um holding fund gerido pelo BEI e participado simultaneamente por FEDER, proveniente das autoridades de gestão regionais, e por capitais nacionais, estes através da Direção- Geral de Tesouro e Finanças. Este fundo de participações foi investido na constituição de cinco fundos de desenvolvimento urbanos (FDU), um por cada região NUTS II do Continente. A gestão dos FDU foi atribuída a entidades financeiras, que podiam ser públicas ou privadas, selecionadas em concurso público em função de um plano de negócio apresentado, das quais se esperava que participassem financeiramente nos FDU alavancando o holding fund com capitais próprios ou alheios. Contratualmente, os FDU podem ser aplicados através de empréstimos, garantias, ou de participação no capital das sociedades promotoras dos projetos urbanos (na prática tem ocorrido apenas o financiamento através de empréstimos), sendo que a definição das modalidades concretas de investimento dos FDU é remetida para os planos de negócio que as entidades gestoras definem.

Um ponto relevante e diferenciador da iniciativa JESSICA quando comparado com outros instrumentos financeiros comunitários é a obrigatoriedade dos utilizadores finais reembolsarem os apoios concedidos (Kalvet et al., 2012). O investimento que utilize financiamento JESSICA terá de ser realizado em 'produto urbano' que gere diretamente rendimento de modo a que o montante reembolsável permita refinanciar novas candidaturas (revolving cycle). Os investimentos têm de ter uma componente de capitais privados (montantes mínimos entre $15 \%$ a $20 \%$ do projeto) e os ativos financiados pelos FDU podem ter adicionalmente alavancagem bancária pela instituição financeira gestora do próprio FDU ou por outra instituição financeira. Os critérios de escolha dos projetos têm em linha de conta a capacidade e velocidade de reembolso, existindo similaridade com os critérios comerciais de seleção de projetos na banca comercial.

Em Portugal, a aprovação dos FDU foi deliberada através de concurso público concluído em setembro de 2011, tendo sido selecionadas três entidades para a sua gestão: o Banco Português de Investimento (BPI), a Caixa Geral de Depósitos (CGD) e o Turismo de Portugal, IP (TdP), tendo este último ganho a gestão dos FDU de Lisboa e do Algarve. Assim, ficou atribuída ao TdP a responsabilidade de análise, seleção e validação dos projetos a apoiar pelos fundos JESSICA nestas duas regiões, a decisão da concessão dos financiamentos, a verificação da elegibilidade das despesas e o acompa- 
nhamento da execução do projeto até à cessação da vigência do contrato de financiamento. Este, no caso de Lisboa, reveste sempre a forma de empréstimo, sendo que o prazo máximo de reembolso é de 15 anos, podendo existir um período de carência máximo de 4 anos.

O JESSICA Holding Fund Portugal foi constituído com uma dotação total de 130 milhões de euros, dos quais 100 milhões correspondem a subscrição de FEDER, embora apenas 5 milhões provenientes da Região de Lisboa. Com a alavancagem, o FDU de Lisboa ficou dotado em 21,2 milhões de euros. Até 2015 este fundo tinha permitido apoiar perto de 20 projetos, representando um volume de investimento total aproximado de 80 milhões de euros. Com a exceção de um pequeno projeto (600 $000 €$ de investimento total) de reabilitação em Sintra, todos os projetos financiados ocorreram na cidade de Lisboa, tendo sido o fundo maioritariamente aplicado em investimentos em hotéis ou outros tipos de alojamento para turistas.

\section{O CASO DO HOTEL SANTIAGO DE ALFAMA}

O Hotel Santiago de Alfama é exemplo de um desses projetos apoiados pelo fundo JESSICA na cidade de Lisboa. Ocupa um imóvel localizado nos números 10 a 14 da Rua de Santiago, entre o Miradouro de Santa Luzia e o Castelo de São Jorge, em pleno centro histórico, numa área com elevada densidade de recursos patrimoniais, museus, restaurantes, galerias e antiquários. Situando-se hoje na freguesia de Santa Maria Maior, pertencia, até à reorganização administrativa de 2012, à freguesia de Santiago, uma das mais antigas, de fundação medieval. O nome do hotel alude a esse topónimo comum da rua e da antiga freguesia.

Apesar de sempre ter havido uma certa diversificação social, o bairro do Castelo e a parte alta de Alfama, onde o hotel se situa, foram preferidos na Idade Média para a habitação de famílias nobres e abastadas, enquanto pescadores e marinheiros viviam maioritariamente perto do rio Tejo (Galhardo, 2014). O imóvel do Hotel Santiago de Alfama tem que ver com esse passado. Começou por ser o paço dos Castros, família que usou o título de condes de Basto e que foi influente durante a união dinástica ibérica, remontando talvez ao século XV (Andrade, 1948). A aparência exterior é sóbria. Como a estrutura sobreviveu ao terramoto de 1755, não foi objeto de grandes reformas modernizantes nem embelezadoras. O edifício impressiona mais pelo volume da massa construída do que pela beleza da fachada. Tem uma área bruta privativa total de $2400 \mathrm{~m}^{2}$ e uma área de implantação de $499,69 \mathrm{~m}^{2}$. Trata-se de um prédio em propriedade total com sete pisos (cinco acima do solo e dois abaixo), composto por dois núcleos adjacentes de volumetrias distintas e origem independente que se interligaram de forma orgânica ao longo da história.

O Hotel situa-se numa área em regressão demográfica há várias décadas. Reconstituindo a evolução populacional na antiga freguesia de Santiago, identifica-se uma primeira fase de crescimento continuado até 1940 (interrompida apenas na década 
da I Guerra Mundial e da gripe pneumónica); a partir dessa altura, segue-se uma segunda fase de declínio, que a década de 50 aparentemente ainda nega (embora o crescimento observado entre 1950 e 60 possa ser devido a uma 'ilusão estatística' resultante da reorganização das freguesias de Lisboa de 1959), mas que se torna ininterrupto desde 1960 (fig. 1). Tal situação, de resto, não é atípica, antes descrevendo uma tendência observada na generalidade do centro histórico de Lisboa.

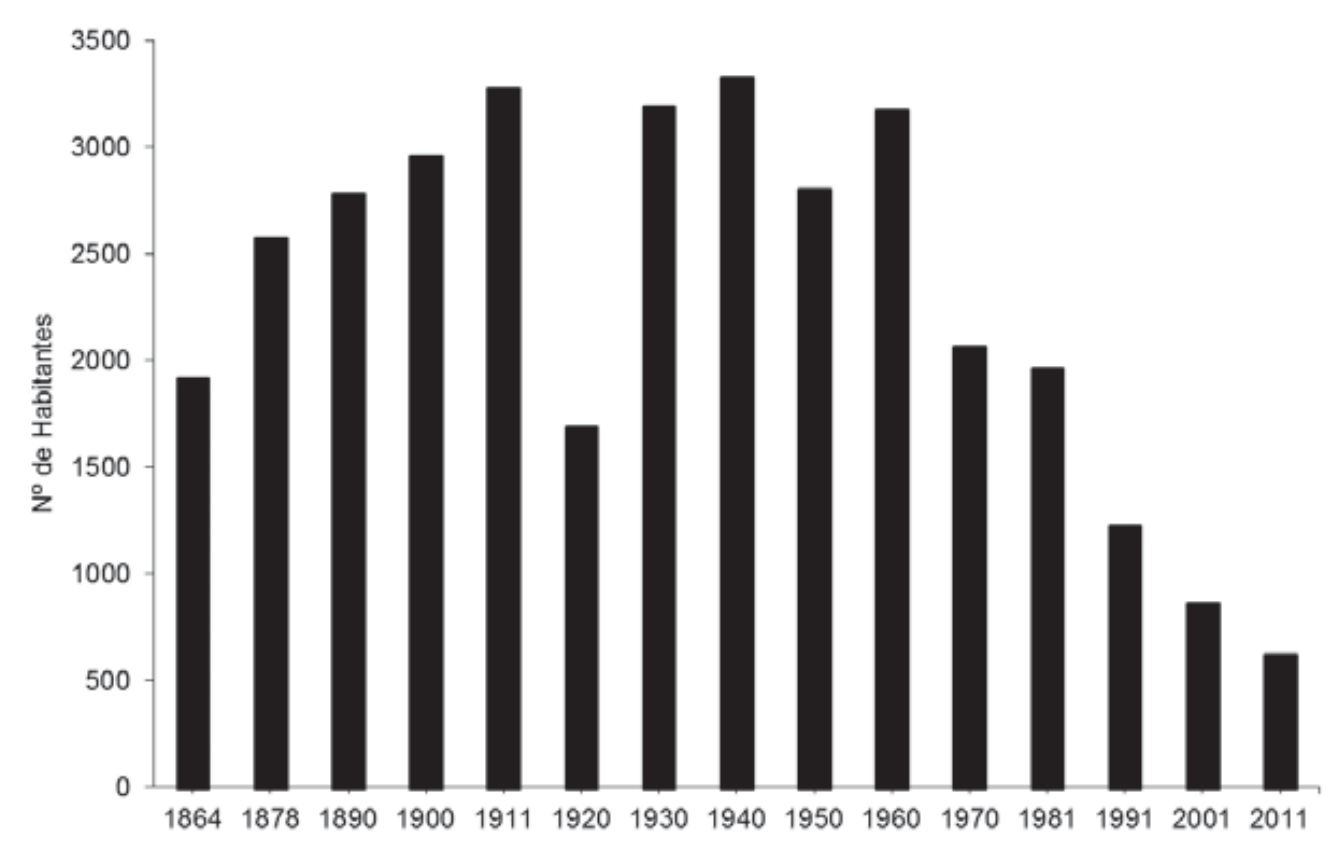

Fig. 1 - Evolução demográfica da antiga freguesia de Santiago, Lisboa.

Fig. 1 - Demographic evolution in former parish Santiago, Lisbon.

Fonte: INE (censos)

A história do edifício aqui em estudo reflete essas tendências de evolução da cidade e a sua análise ajuda a perceber como tais tendências se relacionam com mudanças na estrutura económica, com reconfigurações nas relações de poder e com a entrada e saída de diferentes atores em cena ao longo do tempo.

\section{A fase de proletarização e decadência}

Tende a associar-se o crescimento demográfico das cidades a fases de pujança económica e melhorias no ambiente urbano e a regressão populacional a contextos de crise e degradação do quadro de vida nas cidades. A biografia do edifício do Hotel Santiago de Alfama mostra uma realidade diferente: ao crescimento demográfico que esta parte da cidade experimentou entre meados dos séculos XIX e XX correspondeu uma fase de degradação das condições físicas do imóvel e da ambiência social.

As mudanças no edifício ao longo do século XIX traduzem na sua materialidade transformações mais fundas na estrutura económica, social e política da cidade. O edifício manteve-se por mais de três séculos como habitação nobre. Primeiro, integrado 
na casa de Bastos e depois, talvez por razões políticas, devido à queda em desgraça dos Castros que tomaram o partido filipino na Restauração, na posse dos Pery de Linde, descendentes de mercadores flamengos radicados em Lisboa no século XVI e que a partir do século XVIII encontramos a exercer cargos públicos na corte e funções militares. Mais tarde, a transição da economia de privilégios nobiliárquicos e fundiários típica do Antigo Regime para a nova economia industrial e liberal no século XIX traduz-se na transferência do imóvel para as mãos de um capitalista, Manuel Brás, que o adquire em outubro de 1856 por um conto de réis - um valor baixo, o que sugere que a propriedade estaria desvalorizada - e que por morte o deixará a uma sobrinha-neta, Maria Neves Carvalho (Andrade, 1948).

O declínio dos sistemas domésticos complexos do Antigo Regime sustentados por rendas e comendas, com consanguíneos de vários graus coabitantes e criadagem numerosa, cujo fim definitivo se dá com a afirmação da sociedade burguesa e industrial (Monteiro, 2003), fez com que as casas nobres antigas se tornassem um modelo de habitação obsoleto. A partir do século XIX, a relação dos proprietários com esse tipo de edificado altera-se. Os velhos paços passam a ser vistos como ativos que devem gerar lucro. A industrialização e a procura de habitação pelo proletariado urbano em expansão abrem hipóteses novas de rendibilização do capital imobilizado no edificado. Muitos desses edifícios foram refuncionalizados, subdivididos e acrescentados nos logradouros e terraços, originando o 'pátio' como nova tipologia de habitação plurifamiliar operária (Pereira, 1994).

O edifício do Hotel Santiago de Alfama seguiu essa trajetória de transformação. Os investimentos feitos pelo novo proprietário depois de 1856 foram orientados mais por critérios quantitativos do que qualitativos, com o intuito de permitir maior número de inquilinos através de obras sucessivas e desordenadas de subdivisão e acrescento, e não tanto de beneficiar a qualidade da construção ou a sua habitabilidade. Uma descrição do edifício em Andrade (1948, p. 50) dava conta disso ao fazer referência à "deturpação arquitetónica, [...à] sua fachada de múltiplos e incríveis enxertos, [...aos] vulgaríssimos arranjos de mestre-de-obras, [...e à] amálgama de escadas, saguões, pátios interiores, cubículos improvisados".

Com a morte de Maria Neves Carvalho, em 1933, o imóvel é deixado em testamento à Santa Casa de Misericórdia da sua terra natal, Vila Nova da Barquinha, com a condição de usufruto por parte dos sobrinhos e afilhada. De acordo com comunicações entre os usufrutuários, inquilinos e CML disponíveis no arquivo camarário, o imóvel possuía nessa data 19 fogos habitacionais arrendados. Em 1944 instala-se no piso térreo uma marcenaria, onde, em 1965, por trespasse, se irá estabelecer uma fábrica de camisas e roupa interior - a Sociedade Pinto, Diniz \& $C^{a}$ Lda. -, que também ocupará parte do primeiro andar. Alguns dos operários eram residentes no próprio edifício.

A consulta dos processos relativos a este imóvel no arquivo histórico da CML mostra que esta fase de proletarização do edifício está associada a uma degradação física do edifício. O primeiro registo de intimação da CML aos proprietários para que estes realizem obras de beneficiação data de 1920, em resposta a queixas dos inquilinos. A situação 
agrava-se com a passagem do tempo. Ao longo das décadas de 40 e 50, foram produzidas dez intimações com teor semelhante e subsequentes pedidos para realização de obras. $\mathrm{Na}$ década de 60, há referências a seis vistorias camarárias decorrentes de protestos dos arrendatários e por mudança de inquilinos, todas com escasso ou nenhum resultado uma vez que os usufrutuários vão alegando falta de meios para a realização de obras dado o baixo valor das rendas e o seu condicionamento por imperativos legais. A ruína iminente do imóvel começa a ser referida nas queixas apresentadas pelos inquilinos desde 1968. Da análise dessa documentação, percebem-se como pontos mais críticos o mau estado do telhado com subsequentes infiltrações (graves) de água nas paredes. As más condições do imóvel chegam a produzir vítimas mortais: em 1948, no decurso de obras coercivas destinadas à recuperação do telhado e fachada, morre um trabalhador, por razões que se viriam a atribuir a falta de segurança.

\section{A fase de elitização e renovação associada ao turismo}

Após mais de um século de proletarização e decadência, o rumo do imóvel muda em setembro de 2006. Obtido consentimento dos usufrutuários ainda vivos, a Santa Casa da Misericórdia de Vila Nova da Barquinha vende o edifício (propriedade) a uma sociedade detida por investidores indo-britânicos - a PPNS Properties Portugal Lda. - pelo valor de $375000 €$, a que se somaram mais $135000 €$ pela compra do direito de usufruto aos usufrutuários, já idosos. Este momento marca não apenas a entrada do capital transnacional na história do edifício, como também do turismo. Consumada a aquisição, o novo proprietário negoceia com os últimos inquilinos - um pequeno número de irredutíveis que foram resistindo à degradação do imóvel na expectativa de uma indeminização - a rescisão dos contratos de arrendamento. O imóvel fica totalmente devoluto em 2008. Adicionalmente, faz entrar na CML, em 2007, um pedido de licenciamento para a instalação de uma unidade hoteleira de 4 estrelas de 17 camas, numa área de construção de $1950 \mathrm{~m}^{2}$, que viria a ter deferimento em março de 2010.

A crise financeira de 2008 e a turbulência global que se lhe seguiu atrasa a concretização do projeto. Em maio de 2011, o edifício, devoluto e em estado de pré-ruína, mas com projeto hoteleiro aprovado, passa para a posse de uma sociedade por quotas de direito português - Projecto Rua de Santiago, Unipessoal Lda. -, que é detida por sua vez por uma sociedade de direito inglês - a Lisbon Real Estate Limited, em que esta é detida por uma sociedade de serviços financeiros e gestão de fortunas domiciliada na Ilha de Man - a Isle of Man Assurance Limited (IOMA). O valor de transação foi de $1250000 €$, o que representou enormes mais-valias para a PPNS Lda. (mesmo tendo pago o valor do serviço de arquitetura e indemnizações a antigos moradores e tendo em conta que $420000 €$ foram financiados pelo Barclays Bank, com o imóvel dado como garantia para hipoteca constituída e registada em nome do banco).

Por detrás da sociedade portuguesa, da inglesa e do veículo financeiro da ilha de Man encontra-se um casal de investidores pertencente à nova elite global de gestores e quadros altamente qualificados, ele com dupla nacionalidade portuguesa e inglesa e um currículo 
com passagens por bancos de investimento em Londres e pelo topo da administração da maior empresa de telecomunicações portuguesa, ela de nacionalidade holandesa e infância passada na Nova Zelândia.

A investidora assume o papel de gestora executiva do hotel, bem como a responsabilidade societária e judicial das empresas, sendo gerente na Projecto Rua de Santiago, Unipessoal Lda. e Director na Lisbon Real Estate Limited. Como é comum (normalmente por proteção patrimonial e/ou planeamento fiscal internacional) nas estruturações financeiras internacionais que envolvam jurisdições mais 'opacas' como a da ilha de Man, não se conseguiu obter via informação pública o beneficiário final da sociedade Isle of Man Assurance Limited (IOMA) e a ligação ao referido casal. Presume-se no entanto, através das notícias veiculadas pelos media sobre o hotel e o supracitado casal, bem como das entrevistas que realizámos, que os beneficiários finais da empresa serão essas duas pessoas.

Em 2012, em plena crise, os novos proprietários contratam ao ateliê do arquiteto Luís Rebelo de Andrade uma alteração ao projeto hoteleiro inicial. O programa sugerido consistia na reconversão do imóvel para uma unidade turística de luxo world-class, que se posicionasse no mercado como um dos melhores hotéis de charme da cidade de Lisboa (fig. 2 e 3 ).

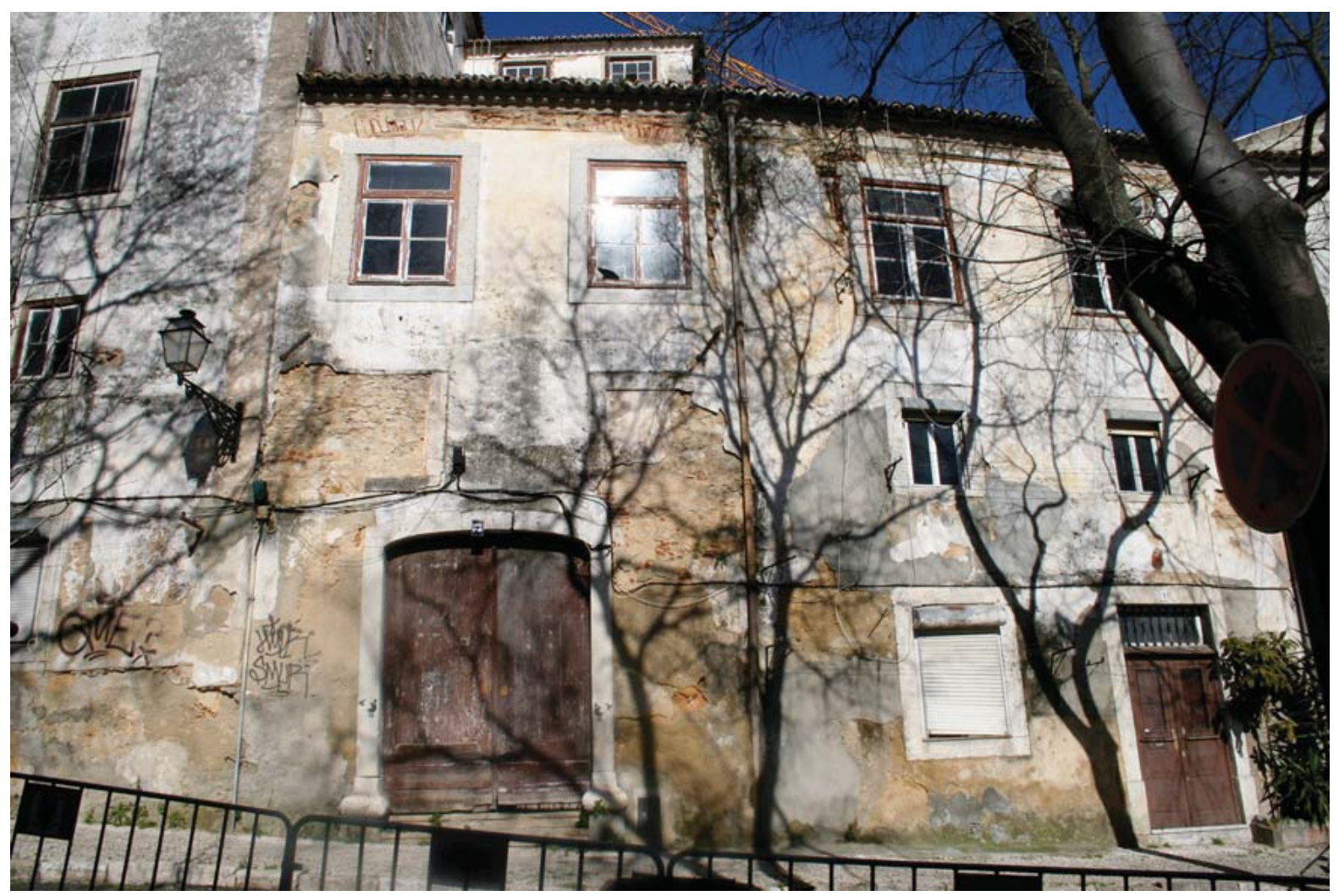

Fig. 2 - O edifício do Hotel Santiago de Alfama (exterior), antes das obras de reabilitação e conversão para unidade hoteleira. Figura a cores disponível online.

Fig. 2 - The Hotel Santiago de Alfama building (outside), before the refurbishment and construction works and conversion into hotel unit. Colour figure available online. 


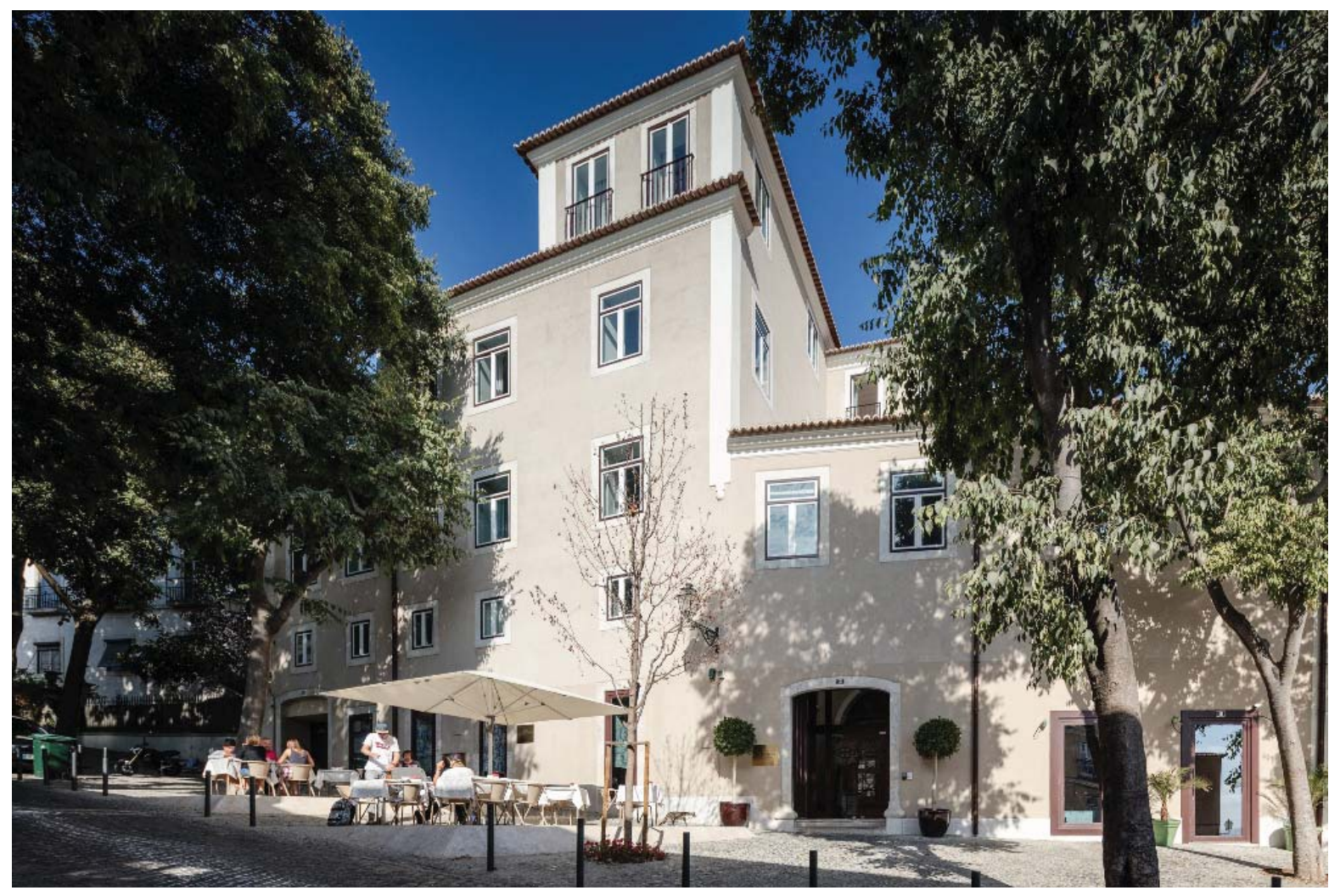

Fig. 3 - O edifício do Hotel Santiago de Alfama (exterior), após as obras de reabilitação e conversão para unidade hoteleira. Figura a cores disponível online.

Fig. 3 - The Hotel Santiago de Alfama building (outside), after the refurbishment and construction works and conversion into hotel unit. Colour figure available online.

Fonte: arquivo de Luís Rebelo de Andrade

O projeto viria a ser submetido à CML em 2013, com a novidade de propor dois novos pisos abaixo do solo para zonas técnicas e serviços do hotel, o que aumentou a área de construção para $2400 \mathrm{~m}^{2}$. A obra, que na fase de infraestruturas e acabamentos ficou a cargo da Construtora San José S.A., pertencente a um grupo baseado em Espanha que opera mundialmente e em cujo portfólio se conta o premiado projeto do Museu do Louvre Abu Dhabi, revestiu particular complexidade, de forma que os trabalhos se estenderam por quase vinte meses. Como explicou o arquiteto responsável pelo projeto em entrevista aos autores, o edifício tinha sido alvo de inúmeras reconstruções e alterações arquitetónicas ao longo dos tempos, à medida das necessidades dos utilizadores e também por escassez de meios financeiros ou controlo camarário e tinha uma estrutura labiríntica; os trabalhos de reabilitação física e construção civil foram por isso exigentes. Além disso, com as obras estendidas ao nível subterrâneo, foi necessário realizar estudos arqueológicos, que atrasaram a conclusão das obras.

No que toca ao investimento e aos meios de financiamento do projeto, o promotor solicitou ao TdP um financiamento JESSICA através do FDU Lisboa logo em 2012. Em outubro desse ano obteve a formalização de um empréstimo JESSICA no montante de 
$1100000 €$, projetando um investimento total de $2436934 €$, para o qual deu como garantia (hipoteca voluntária) o próprio imóvel. Segundo confirmou o proprietário em entrevista, esse empréstimo foi crucial para o desenvolvimento do projeto numa altura em que Portugal se encontrava sob um programa de resgate financeiro, em recessão económica e com a maioria da banca tradicional a limitar fortemente o crédito por falta de recursos próprios e a considerar o imobiliário atividade não financiável.

À data da candidatura ao fundo JESSICA, era ainda a proposta inicial de criação de um hotel de 4 estrelas que estava em cima da mesa. Com o novo projeto de reabilitação e a alteração do programa para um hotel de 5 estrelas, o montante do investimento total disparou para os $3500000 €$. Para além das obras de remodelação do edifício, foi canalizado importante investimento para o design de interiores e ambiência. Assim, adicionalmente ao fundo JESSICA, a sociedade promotora solicitou em outubro de $2013 \mathrm{um}$ financiamento junto da banca comercial, desta feita ao Banco Popular Portugal S.A., no montante de $1050000 €$, dando novamente o imóvel como hipoteca. Em 2015, foi obtido um último reforço de financiamento pelo mesmo banco no valor de $350000 €$, com registo de uma terceira hipoteca sobre o mesmo imóvel.

Inaugurado em julho de 2015, o Hotel Santiago de Alfama é atualmente uma unidade hoteleira de 5 estrelas, com 6 suites e 13 quartos, restaurante de autor (o Fábrica de Santiago, nome que é uma alusão pós-industrial à memória do imóvel), cabeleireiro e salão de massagens, além de uma loja de produtos regionais gourmet. No final de 2015, segundo o relatório e contas da empresa proprietária, tinha ao serviço 25 trabalhadores, com um custo médio por empregado de cerca de $14000 € /$ ano.

Em termos de nicho de mercado, a unidade enquadra-se na categoria de 'hotel boutique'. Anhar (2001) e Aggett (2007) descrevem este género de alojamento como um hotel de pequena dimensão, único, intimista, de arquitetura e decoração diferenciadas, customizado e com elevada qualidade e personalização do serviço, sendo por norma mais caro que o hotel de cadeia. $\mathrm{O}$ mercado alvo do hotel boutique são consumidores com gosto por design, atentos às 'tendências e estilo de vida' (trends \& lifestyle), que se querem sentir membros de uma comunidade global que aprecia experiências costumizadas e a sofisticação de locais elitizados (Strannegard \& Strannegard, 2012). Tal como sucede aqui, consumidores deste tipo de unidades procuram espaços com uma ambiência e estética que reflitam 'estilo de vida', identidade e um posicionamento de diferenciação e elevado status social (Strannegard \& Strannegard, 2012).

A atmosfera do Hotel Santiago de Alfama é intimista, sofisticada e eclética. A proprietária e também gerente do hotel concebeu a decoração numa interpretação própria da identidade do lugar, introduzindo pormenores pessoais que criam um sentido de domesticidade. Os pátios interiores, com as suas cisternas de água, têm ressonâncias orientalizantes que remetem para o passado árabe de Alfama. Os quartos são amplos, com áreas que variam entre os 22,5 e os $50 \mathrm{~m}^{2}$, de cores suaves e decoração clean, ponteados por detalhes únicos, como largas banheiras de tina pousadas sobre painéis de mosaico hidráulico, menus de almofadas e pequenas zonas de repouso. Muito do mobiliário foi concebido propositadamente para o hotel e a decoração apostou em layouts diferentes em 
cada quarto, de forma a acomodar uma individualidade própria. O investimento em obras de arte, de várias origens e trazidas em grande parte pela proprietária nas suas viagens pelo mundo, é notório, coexistindo pinturas de artistas contemporâneos com pequenos móveis e antiguidades indianos e do sudeste asiático, azulejos e mármores portugueses.

O ambiente social do Hotel Santiago de Alfama é cosmopolita. Os hóspedes são em larga maioria estrangeiros que procuram um serviço personalizado, design, charme e história. Como referido por Strannegard e Strannegard (2012), este tipo de clientes, por dominarem os códigos de gosto e comportamentos cosmopolitas, sente-se 'em casa' neste tipo de propriedades, independentemente de estarem em Lisboa ou noutra cidade mundial.

Em termos de marketing e canais de vendas, o Hotel Santiago de Alfama tem um website próprio com possibilidades de efetuar reservas, página oficial de Facebook e trabalha quer com websites multioferta e generalistas, como o www.booking.com e o www.hotels.com, quer com websites mais dirigidos para o mercado de luxo e hotelaria de charme, como o www.secretplaces.com ou o www.i-escape.com. O hotel tem sido alvo de diversas reportagens em revistas nacionais e internacionais dedicadas ao turismo de luxo, como a CondéNast Traveller, a Méditerranée Magazine e o Telegraph Travel. Os preços de quarto/noite com pequeno-almoço variam entre os 210 e os $340 €$ - o que significa que cada quarto produz hoje, num dia, rendimento superior ao que provavelmente, antes da conversão do edifício em hotel, se auferia num mês inteiro com o total das rendas dos antigos inquilinos.

\section{DICUSSÃO FINAL E CONCLUSÃO}

Na biografia do edifício do Hotel Santiago de Alfama podemos ver refletidas sucessivas fases da história urbana de Lisboa. As metamorfoses por que o edifício passou - de casa nobre para pátio operário, de pátio operário para hotel de luxo - exprimem a adaptação do imóvel a essas mudanças - a industrialização, no primeiro caso; a turistificação associada à restruturação urbana pós-industrial, no segundo - com consequências na paisagem, ao nível da materialidade do edificado e na atmosfera do lugar, assim como no ambiente social. Muito sintomaticamente, no mesmo imóvel onde existiram em tempos dezanove apartamentos sombrios e húmidos, destinados a famílias trabalhadoras pobres, estão hoje dezanove quartos e suites espaçosos e arejados, bem decorados, por onde circula a nova elite global de viajantes endinheirados, e um restaurante de chef veio ocupar o lugar onde existiu uma fábrica de camisas.

Analisando a história deste edifício, percebe-se que as transmutações que ele foi sofrendo ao longo do tempo estiveram associadas a diferentes estratégias de valorização do capital imobilizado no ambiente construído, em função do que em cada momento surgia como oportunidade mais viável de rentabilização do investimento. O próprio processo de proletarização do edifício, ocorrido durante o ciclo urbano da industrialização, 
foi em si uma forma de tentar maximizar o lucro. Por outro lado, olhando para este caso em concreto, é visível que não se podem entender as razões da turistificação urbana desligadas das estratégias do imobiliário. A conversão do edifício em hotel surge porque, num contexto pós-industrial e de globalização, isso aparece como uma forma de rentabilização rápida e eficiente do capital imobiliário. A alavancagem no crédito é outro dado essencial a reter nesta história. É ela que catapulta o projeto turístico-imobiliário em questão para um escalão world-class, permitindo ao hotel posicionar-se globalmente como um produto diferenciado. A estreita imbricação das esferas turismo-imobiliário-banca ressalta deste estudo de caso como algo essencial para compreender a turistificação urbana.

O nexo entre globalização, turismo e reestruturação urbana, bastante sublinhado na literatura, surge em grande destaque nesta história. A dimensão global está presente não apenas pelo facto do hotel operar nesse mercado, mas também porque provieram desse espaço os protagonistas essenciais da conversão do edifício em hotel. O Hotel Santiago de Alfama é portanto, a vários títulos, incluindo na atmosfera cosmopolita que nele se vive, um enclave da globalização no tecido da cidade. Este facto é relevante porque revela um lado menos referido na literatura sobre globalização e reestruturação urbana: a introdução do capital transnacional na regeneração urbana está a ser realizado também por investidores privados em pequenas promoções e não apenas por grandes projetos imobiliários desenvolvidos por fundos de investimento que operam à escala do quarteirão, ou por grandes consórcios de investidores alavancados nos mercados financeiros globalizados, como a literatura tende mais frequentemente a referir. Este estudo de caso mostra ainda que são múltiplos os atores que intervêm na turistificação da cidade e na gentrificação turística: não apenas as grandes cadeias de hotéis e cafés (Gotham, 2005), não apenas os pequenos investidores que deslocam fogos para o arrendamento de curta duração (Füller \& Michel, 2014), mas também investimentos hoteleiros independentes e diferenciados, conduzidos por investidores individuais integrados nos circuitos do capital global e com bom acesso ao crédito.

O mix de design, memória, consumo e imobiliário, tantas vezes sublinhado na literatura como sendo a 'fórmula mágica' da reestruturação urbana pós-industrial ou pós-moderna (v., e.g., Hannigan, 1998; Zukin, 2010), está bem presente também no caso analisado, se bem que aqui numa escala micro. Esse investimento no ambiente construído, muito articulado com a economia dos signos, está na origem da elitização do local. Muitas das questões levantadas na literatura a respeito do caráter excludente dos espaços turistificados têm aplicação aqui. Contudo, a biografia do edifício e o caso concreto do hotel estudado mostram também que culpar a turistificação pela expulsão dos residentes e como fonte de conflitos sociais nem sempre é adequado. O investimento turístico apareceu neste caso após um caminho de degradação e abandono progressivo do edifício que claramente vinha de muito antes das políticas neoliberais. Tão-pouco se pode dizer que o capital globalizado e a turistificação tenham sido responsáveis por corromper uma harmonia social pré-existente. O passado pré-turístico do local estava já impregnado de histórias pessoais de privação, exclusão e injustiça, e marcado por uma forte tensão social e conflitualidade entre inquilinos e proprietários. 
Por último, uma nota acerca do papel da iniciativa JESSICA neste processo. Como instrumento de política neoliberal que é, percebe-se que não teve por finalidade regular ou orientar, contrariar ou corrigir o mercado, mas sim coadjuva-lo subsidiariamente, desbloqueado dificuldades de crédito e facilitando os investimentos.

O caso em concreto do Hotel Santiago de Alfama mostra que a opção de investir na hotelaria tinha sido equacionada antes da iniciativa JESSICA estar no terreno. O fundo JESSICA talvez não deva portanto ser visto como causa da turistificação da cidade de Lisboa, mas como um elemento facilitador desse processo, que num período crítico de bloqueio do acesso ao crédito na banca tradicional funcionou como seu substituto e, por isso, foi crucial.

\section{AGRADECIMENTOS}

Os autores agradecem aos entrevistados o tempo que disponibilizaram e os dados que forneceram para a reconstituição da biografia do edifício, especialmente ao Arq. Luís Rebelo de Andrade, que facilitou o acesso ao seu arquivo pessoal, e à direção do Hotel Santiago de Alfama, por abrir as portas para a pesquisa de campo.

\section{REFERÊNCIAS BIBLIOGRÁFICAS}

Aggett, M. (2007). What has influenced growth in the UK's boutique hotel sector? International Journal of Contemporary Hospitality Management, 19(2), 169-177.

Althaus, E., \& Glaser, M. (2015). Legacies of modernism. House-biographies of large post-war residential complexes in Switzerland. In F. Zanfi \& G. Caramellino (Eds.), Post-war middle-class housing: Models, construction and change (pp. 243-262). Berna: Peter Lang.

Andrade, F. (1948). A freguesia de Santiago. Subsídios para a história das suas ruas, edifícios e igreja paroquial [The freguesia of Santiago. Subsidies for the history of its streets, buildings and parish church]. Lisboa: Câmara Municipal de Lisboa.

Andrade, M., \& Lamela, C . (2015, agosto). Tourism without gentrification? Obstacles to achieve a "Happy Medium". Comunicação apresentada à $12^{\text {th }}$ Conference of the European Sociological Association, Praga, República Checa.

Anhar, L. (2001). The definition of boutique hotels. Retrived from: http://www.hospitalitynet.org/ news/4010409.html
Ashworth, G., \& Page, S. (2011). Urban tourism research: recent progress and current paradoxes, Tourism Management, 32(1), 1-15.

Barata Salgueiro, T. (1994). Novos produtos imobiliários e reestruturação urbana [Real estate new products and urban restructuring]. Finisterra Revista Portuguesa de Geografia, XXIX(57), 79-101.

Barata Salgueiro, T. (2001). Lisboa, periferia e centralidades [Lisbon, outskirts and centralities]. Oeiras: Celta.

Barata Salgueiro, T., André, I., \& Brito-Henriques, E. (2015). A política de cidades em Portugal: instrumentos, realizações e perspetivas [Urban policy in Portugal: tools, achievements and prospects]. In P. Neto \& M. M. Serrano (Eds.), Politicas públicas, economia e sociedade. Contributos para a definição de políticas no período 2014-20 [Public policies, economy and society. Contributions for the policies definition in the period 2014-20] (pp. 49-81). Alcochete: Smartbook

Barata Salgueiro, T., Mendes, L., \& Guimarães, P. (2017). Tourism and urban changes: lessons from Lisbon. In M. Gravari-Barbas, \& S. Guinand (Eds), 
Tourism and Gentrification in Contemporary Metropolises. International Perspectives (pp. 255-275). Oxon: Routledge,

Beriatos, E., \& Gospodini, A. (2004). "Glocalising" urban landscapes: Athens and the 2004 olympics. Cities, 21(3), 187-202.

Blunt, A. (2008). The 'skyscraper settlement': home and residence at Christodora House. Environment and Planning A, 40(3), 550-571.

Blunt, A., \& Dowling, R. (2006). Home. Abingdon e New York: Routledge.

Brito-Henriques, E. (1996). A Lisboa turística, entre o imaginário e a cidade. A construção de um lugar turístico urbano [The Tourist Lisbon, between the imagery and the city. The building of an urban tourism place]. Lisboa: Edições Colibri.

Broudehoux, A.-M. (2007). Spectacular Beijing: the conspicuous construction of an olympic metropolis. Journal of Urban Affairs, 29(4), 383-399.

Cócola Gant, A. (2015, agosto). Tourism and commercial gentrification. Comunicação apresentada à International Conference 'The ideal city. Between myth and reality', Urbino, Itália.

Dirksmeier, P., \& Helbrecht, I. (2015). Resident perceptions of new urban tourism: a neglected geography of prejudice. Geography Compass, 9(5), 276-285.

Edwards, D., Griffin, T., \& Hayllar, B. (2008). Darling Harbour: looking back and moving forward. In B. Hayllar, T. Griffin, \& D. Edwards (Eds.), City spaces - tourist places: Urban tourism precincts (pp. 275-294). Oxford e Burlington, MA: Butterworth-Heinemann.

Fainstein, S. S. (1990). The changing world economy and urban restructuring. In D. R. Judd, \& M. Parkinson (Eds.), Leadership and urban regeneration (pp. 31-47). Thousand Oaks, CA: Sage.

Fainstein, S. S. (2008). Mega-projects in New York, London and Amsterdam. International Journal of Urban and Regional Research, 32(4), 768-785.

Fainstein, S. S. \& Judd, D. R. (1999). Cities as places to play. In D. R. Judd \& S. S. Fainstein (Eds.), The tourist city (pp. 261-272). New Haven CT: Yale University Press.

Foley, M., \& Mcpherson, G. (2007). Glasgow's Winter Festival: can cultural leadership serve the common good? Managing Leisure, 12 (2), 143-156.
Füller, H., \& Michel, B. (2014). 'Stop being a tourist!' New dynamics of urban tourism in Berlin-Kreuzberg. International Journal of Urban and Regional Research, 38, 1304-1318.

Galdini, R. (2007). Tourism and the city: opportunity for regeneration. Tourismos: An International Multidisciplinary Journal of Tourism, 2(2), 95-111.

Galhardo, J. (2014). As desigualdades fontes de dinâmicas urbanas no centro histórico de Lisboa [Inequalities of sources of urban dynamics in the Lisbon historic centre]. Cadernos Metrópole, 16(32), 513-536.

Gladstone, D., \& Préau, J. (2008). Gentrification in tourist cities: evidence from New Orleans before and after Hurricane Katrina. Housing Policy Debate, 19(1), 137-175.

Goh, D. (2010). Capital and the transfiguring monumentality of Raffles Hotel. Mobilities, 5(2), 177-195.

Goss, J. (1996). Disquiet on the waterfront: reflections on nostalgia and utopia in the urban archetypes of festival marketplaces. Urban Geography, 17(3), 221-247.

Gotham, F. (2005). Tourism gentrification: The case of new Orleans' vieux carre (French Quarter). Urban Studies, 42(7), 1099-1121.

Guimarães, P. (2016). A eficácia dos projetos especiais de urbanismo comercial. Evidências de Braga [The effectiveness of the special projects of commercial urbanism. Evidence from Braga]. Finisterra - Revista Portuguesa de Geografia, LI(102), 47-64.

Hackworth, J. (2006). The neoliberal city. Governance, ideology, and development in American urbanism. Ithaca: Cornell University Press.

Jansen-Verbeke, M. \& Lievois, E. (1999). Analysing heritage resources for urban tourism in European cities. In D. G. Pearce, \& Richard W. Butler (Eds.), Contemporary issues in tourism development (pp. 81-106). Londres e Nova Iorque: Routledge.

Hannigan, J. (1998). Fantasy city: Pleasure and profit in the postmodern metropolis. Londres e Nova Iorque: Routledge.

Harvey, D. (1982). The limits to capital. Oxford: Basil Blackwell.

Kalvet, T., Vanags, A., \& Maniokas, K. (2012). Financial engineering instruments: the way forward for cohesion policy support? Recent experience from the Baltic states. Baltic Journal of Economics, 12(1), 5-22. 
Jacobs, J., Cairns, S., \& Strebel, I. (2012). Doing building work: methods at the interface of geography and architecture. Geographical Research, 50(2), 126-140.

Judd, D. R. (2003). Visitors and the spatial ecology of the city. In L. Hoffman, S. S. Fainstein, \& D. R. Judd (Eds.), Cities and visitors: Regulating people, markets, and city space (pp. 23-38). Oxford: Blackwell.

Lash, S., \& Urry, J. (1994). Economies of signs and space. Londres e Thousand Oaks, CA: Sage.

Law, C. (1992). Urban tourism and its contribution to economic regeneration. Urban Studies, 27(3), 599-618.

Lloyd, R. (2002). Neo-bohemia: art and neighborhood redevelopment in Chicago. Journal of Urban Affairs, 24(5), 517-532.

Lloyd, R., \& Clark, T. N. (2001). The city as an entertainment machine. In K. F. Gotham (Ed.), Critical Perspectives on Urban Redevelopment (pp. 357-378). Nova Iorque: Elsevier.

McCarthy, J. (1998). Reconstruction, regeneration and re-imaging: the case of Rotterdam. Cities, 15(5) 338-341.

McCarthy, J., \& Pollock, A. S. (1997). Urban regeneration in Glasgow and Dundee: a comparative evaluation. Land Use Policy, 14(2), 137-148.

Monteiro, N. G. (2003). O crepúsculo dos grandes. A casa e o património da aristocracia em Portugal (1750-1832) [The twilight of nobility. The manor and patrimony of the aristocracy in Portugal (1750-1832)]. Lisboa: Imprensa Nacional-Casa da Moeda

Orueta, D. (2007). Madrid: urban regeneration projects and social mobilization. Cities, 24(3), 183-193.

Peck, J., Theodor, N., \& Brenner, N. (2009). Neoliberal urbanism: models, moments, mutations. SAIS Review of International Affairs, 29(1), 49-66.
Pereira, N. T. (1994). Pátios e vilas de Lisboa, 1870-1930: a promoção privada do alojamento operário. Análise Social, XXIX(127), 509-524.

Rofe, M. W. (2003). 'I want to be global': theorising the gentrifying class as an emergent élite global community. Urban Studies, 40(12), 2511-2526.

Sager, T. (2011). Neo-liberal urban planning policies: a literature survey 1990-2010. Progress in Planning, 76(4), 147-199.

Sassen, S. (2000). Cities in a world economy ( $2^{\mathrm{a}}$ ed.). Thousand Oaks, CA: Pine Forge Press.

Selby, M., Hayllar, B., \& Griffin, T. (2008) The tourist experience of precincts. In B. Hayllar, T. Griffin, \& D. Edwards (Eds) City spaces, tourist places: Urban tourism precincts (pp. 183-201). Amsterdão: Butterworth-Heinemann.

Sklair, L. (2006). Iconic architecture and capitalist globalization. City, 10(1), 21-47.

Skoll, G. R., \& Korstanje, M. (2014). Urban heritage, gentrification, and tourism in Riverwest and $\mathrm{El}$ Abasto. Journal of Heritage Tourism, 9(4), 349-359 .

Smith, N. (2002). New globalism, new urbanism: gentrification as global urban strategy. Antipode, 34(3), 427-450.

Soja, E., Morales, R., \& Wolff, G. (1983). Urban restructuring: an analysis of social and spatial change in Los Angeles. Economic Geography, 59(2), 195-230.

Stake, R. E. (1995). The art of case study research. Thousand Oaks, CA: Sage.

Strannegard, L., \& Strannegard, M. (2012). Works of art: aesthetic ambitions in design hotels. Annals of Tourism Research, 39(4), 1995-2012.

Tallon, A. (2010). Urban regeneration in the UK. Oxon e Nova Iorque: Routledge.

Zukin, S. (2010). The naked city: The death and life of authentic urban places. Nova Iorque: Oxford University Press. 